\title{
Critical inspiratory pressure - a new methodology for evaluating and training the inspiratory musculature for recreational cyclists: study protocol for a randomized controlled trial
}

Patricia Rehder-Santos ${ }^{1}$, Vinicius Minatel ${ }^{1}$, Juliana Cristina Milan-Mattos ${ }^{1}$, Étore De Favari Signini ${ }^{1}$, Raphael Martins de Abreu', Carla Cristina Dato ${ }^{2}$ and Aparecida Maria Catai ${ }^{1 *}$ (D)

\begin{abstract}
Background: Inspiratory muscle training (IMT) has brought great benefits in terms of improving physical performance in healthy individuals. However, there is no consensus regarding the best training load, as in most cases the maximal inspiratory pressure (MIP) is used, mainly the intensity of $60 \%$ of MIP. Therefore, prescribing an IMT protocol that takes into account inspiratory muscle strength and endurance may bring additional benefits to the commonly used protocols, since respiratory muscles differ from other muscles because of their greater muscular resistance. Thus, IMT using critical inspiratory pressure (PThC) can be an alternative, as the calculation of PThC considers these characteristics. Therefore, the aim of this study is to propose a new IMT protocol to determine the best training load for recreational cyclists.

Methods: Thirty recreational cyclists (between 20 and 40 years old) will be randomized into three groups: sham (SG), PThC (CPG) and 60\% of MIP, according to age and aerobic functional capacity. All participants will undergo the following evaluations: pulmonary function test (PFT), respiratory muscle strength test (RMS), cardiopulmonary exercise test (CPET), incremental inspiratory muscle endurance test (ilME) (maximal sustained respiratory pressure for 1 min (PTh MAX) $_{\text {) and constant load test (CLT) (95\%, 100\% and 105\% of PTh }}$ MAX) using a linear load inspiratory resistor (PowerBreathe K5). The PThC will be calculated from the inspiratory muscle endurance time $\left(T_{L I M}\right)$ and inspiratory loads of each CLT. The IMT will last 11 weeks ( 3 times/week and $55 \mathrm{~min} / \mathrm{session}$ ). The session will consist of 5-min warm-up (50\% of the training load) and three sets of 15-min breaths (100\% of the training load), with a 1min interval between them. RMS, iIME, CLT and CPET will be performed beforehand, at week 5 and 9 (to adjust the training load) and after training. PFT will be performed before and after training. The data will be analyzed using specific statistical tests (parametric or non-parametric) according to the data distribution and their respective variances. A $p$ value $<0.05$ will be considered statistically significant.
\end{abstract}

Discussions: It is expected that the results of this study will enable the training performed with PThC to be used by health professionals as a new tool to evaluate and prescribe IMT.

Trial registration: ClinicalTrials.gov, NCT02984189. Registered on 6 December 2016.

Keywords: Physical exercise, Physiotherapy, Physical performance, Critical power, Respiratory muscle

\footnotetext{
* Correspondence: mcatai@ufscar.br; amcatai50@gmail.com

${ }^{1}$ Cardiovascular Physical Therapy Laboratory, Nucleus of Research in Physical Exercise, Department of Physical Therapy, Federal University of São Carlos, Via Washington Luiz, km 235, CP: 676, São Carlos, São Paulo 13565-905, Brazil Full list of author information is available at the end of the article
}

(c) The Author(s). 2019 Open Access This article is distributed under the terms of the Creative Commons Attribution 4.0 International License (http://creativecommons.org/licenses/by/4.0/), which permits unrestricted use, distribution, and reproduction in any medium, provided you give appropriate credit to the original author(s) and the source, provide a link to the Creative Commons license, and indicate if changes were made. The Creative Commons Public Domain Dedication waiver (http://creativecommons.org/publicdomain/zero/1.0/) applies to the data made available in this article, unless otherwise stated. 


\section{Background}

Positive results obtained using inspiratory muscle training (IMT) in active and non-active healthy individuals have transformed this type of intervention into one of the most studied in recent decades [1-3]. IMT, which is already used as an integral part of cardiorespiratory rehabilitation in individuals with respiratory muscle weakness [4-6], is currently an alternative for improving the athletic performance of amateur and professional athletes by reducing the sensation of dyspnea in these individuals [7-15].

However, despite the large number of studies that evaluate the efficiency of IMT, there is a gap in the literature related to choosing the best protocol for each population and training objective. Thus, new studies need to be carried out aimed at establishing the best load (intensity), duration and frequency of training for healthy active individuals and to promote central and peripheral adaptations, which can help regulate respiratory muscle activity [16].

Among these parameters, the most studied is the training load, but there is still no consensus as to which is the best load to use. Thus, respiratory muscle strength (RMS) measurements have mainly been used in published studies and the percentage of maximal inspiratory pressure (MIP) is most commonly used for establishing training loads $[16,17]$. However, as well as RMS, respiratory muscle endurance (RME) should also be considered, as together they make up the main characteristics of the respiratory system, and can bring about greater systemic adjustments, leading to an improvement in physical performance as the respiratory muscles stand out from the other muscles due to their great resistance [18].

According to Hajghanbari et al. [3], the loads presented in the studies cited in this review used training intensities between $50 \%$ and $80 \%$ of MIP. In a review by Janssens et al. [19], the authors concluded that changes in inspiratory muscle strength (IMS) were more significant in training with loads between $60 \%$ and $80 \%$ of MIP. Thus, most of the studies that show good results after the IMT $[3,19]$ used the $60 \%$ load of MIP. However, to the best of our knowledge, no new methods have been published that use the IMS and inspiratory muscle endurance (IME) together to determine the training load.

Based on this, it was proposed in our group's previous research to determine the critical inspiratory pressure (PThC) of apparently healthy young and middle-aged men during IME [20]. This new methodology to determine the training load was based on the concept of critical power defined as the limit work $\left(\mathrm{W}_{\text {LIM }}\right)$ where an exercise can be maintained for a long period of time $\left(\mathrm{T}_{\text {LIM }}\right)$ without any signs of fatigue $[21,22]$ or as the intensity where the aerobic and anaerobic pathways are recruited together [23].
The determination of PThC is performed by the total work (abscissa) graph for the total time to exhaustion (coordinate), from multiple intensities of exercise to fatigue. Once this is done, a linear regression of the points is performed to identify the curvature constant ( $\left.\mathrm{W}^{\prime}\right)$ and the PThC is determined as the point at which the line intersects the abscissa. This work-time relationship is defined by a hyperbolic function, in which the slope represents the aerobic function and the intercept in $y\left(\mathrm{~W}^{\prime}\right)$, the anaerobic working capacity, that is, the maximal workload that can be performed using stored energy in the active muscle (adenosine triphosphate, phosphocreatine, glycogen and myoglobin-bound oxygen) [24, 25]. In addition, it should be noted that both IMS and IME are used to determine it; the latter by evaluating $\mathrm{PTh}_{\mathrm{MAx}}$, which represents the maximal workload that the individual can sustain for at least $1 \mathrm{~min}$ [26-29].

Thus, it was observed that the percentage of PThC is similar to other values of critical power identified in the literature, where PThC and the percentage of $\mathrm{PTh}_{\mathrm{MAx}}$ are influenced by age [20]. This suggests that the concept of PThC can be applied as a new IMT tool, as this method considers the characteristics of the respiratory musculature, i.e., IMS and IME together [20].

In addition, during the proposition of a new training load, the results of this new methodology need to be compared with the other loads found in the literature to clarify what the best training intensity is for a given population and to define the responses generated by this training in the main systems involved: the cardiovascular, respiratory and metabolic systems.

IMT using PThC can bring additional benefits, such as increased oxygen uptake $\left(\mathrm{VO}_{2 \mathrm{PEAK}}\right)$, generated by using a moderate to high intensity load that can be performed over a long period of time [23] due to improving the efficiency of respiratory, cardiovascular and musculoskeletal systems and which will contribute to improved physical performance. In addition, a longer delayed mechanism of inspiratory muscle metaboreflex has been pointed out as one of the main factors responsible for the benefits of IMT in healthy individuals $[3,19]$.

\section{Methods \\ Aim}

The aim of this study is to propose a new methodology to determine the IMT load for recreational cyclists, which promotes better results for physical performance and for cardiovascular, respiratory and metabolic responses compared to traditional methodologies.

\section{Primary outcome measures}

The primary outcome measure is the performance on exercise: peak oxygen uptake $\left(\mathrm{VO}_{2 \mathrm{PEAK}}\right)$ and work load 
(W) were obtained by cardiopulmonary exercise testing (CPET).

\section{Secondary outcome measures}

The secondary outcome measures are as follows:

- The cardiovascular responses to IMT: systolic arterial pressure (SAP), dyastolic arterial pressure (DAP), heart rate (HR), cardiac output (CO), stroke volume (SV) and total peripheral vascular resistance (PVR) will be evaluated during the CPET and incremental inspiratory muscle endurance test (iIME).

- The respiratory responses to IMT: carbon dioxide production $\left(\mathrm{VCO}_{2}\right)$, respiratory exchange rate (RER), respiratory rate (RR), respiratory ventilation (VE), oxygen uptake efficiency slope (OUES) and minute ventilation-carbon dioxide production slope (VE/VCO $\left.\mathrm{VCLOPE}_{2}\right)$ will be monitored and registered during CPET and iIME. MIP and MEP will be collected in the RMS test. The pulmonary function test (PFT) index comprises: slow and forced vital capacity (SVC and FVC), maximal voluntary ventilation (MVV), forced expiratory volume in $1 \mathrm{~s}\left(\mathrm{FEV}_{1}\right)$, relationship between $\mathrm{FEV}_{1}$ and $\mathrm{CVF}\left(\mathrm{FEV}_{1} / \mathrm{FVC}\right), \mathrm{IC}$, expiratory reserve volume (ERV) and MVV.

- The metabolic responses to IMT: oxyhemoglobin $\left(\mathrm{O}_{2} \mathrm{Hb}\right)$, deoxyhemoglobin $(\mathrm{HHb})$ and total hemoglobin $(\mathrm{tHb})$ and $\mathrm{VO}_{2 \text { PEAK }}$ responses will be measured during CPET and iIME.

\section{Study design}

This is an experimental, longitudinal, randomized, controlled and double-blind study. The research participants and the researcher (PRS), who will perform the evaluation and reevaluation protocols and statistical analysis, will be blinded. The researcher who will carry out the study analyses (tabulation, data processing and statistical analyses) will not participate in the randomization and training of the participants. Thus, after tabulating all the data, the same person (PRS) will receive a table of data from the other researchers, separated by training groups, using codes to perform the statistical analysis. The participants will be blinded to the training loads to which they are being submitted, by means of a barrier fixed on the computer screen. The methodological design was based on the Standard Protocol Items: Recommendations for Interventional Trials (SPIRIT) (Additional file 1) [30].

\section{Subjects}

Thirty recreational male cyclists, aged between 20 and 40 years, will be evaluated. They will be randomly divided into three groups: sham group (SG), PThC group
(CPG) and $60 \%$ of the MIP group (60G). The groups will be formed by the randomization of the paired individuals with the same aerobic functional classification [31] and age group (subdivided into decades), using $\mathrm{R}$ software 3.0.2 to allocate the subjects.

The criteria used to select the participants will be as follows: male subjects aged 20 to 40 years old, apparently healthy, who have been practicing cycling for at least 6 consecutive months and at least $150 \mathrm{~min} /$ week (classified as active by the American College of Sports Medicine [32]). In addition, participants must not have abnormalities in the cardiovascular, respiratory, musculoskeletal or neurological systems, nor of other systems that make the proposed tests impossible. The exclusion criteria of the study are as follows: participants with electrocardiogram (ECG) changes (ischemia, overload, severe arrhythmias (such as ventricular tachycardia) and conduction disorders), both at rest and during the clinical exercise test, obesity (body mass index (BMI) $>30$ $\mathrm{kg} / \mathrm{m}^{2}$ ), diabetes mellitus, hypertension, alterations in the results of laboratory tests, participants with respiratory muscle weakness (MIP $<60 \%$ predicted [33]), smokers or former smokers with at least 1 year of interruption, alcoholics and users of illicit drugs or medication that may interfere with the results of the research and participants who have performed some type of IMT the last 12 months.

The participants will be recruited by electronic and printed media and by contact with subjects included in the database of the Laboratory of Cardiovascular Physiotherapy (LFCV) at the Federal University of São Carlos (UFSCar). Once identified, eligible participants will be invited to participate in the study and after they have accepted, they will carry out all the evaluations described subsequently and the type of training to which they are allocated.

\section{Study planning}

The present study will be conducted in accordance with the Helsinki Declaration. This study was approved by the Human Research Ethics Committee at the Federal University of São Carlos (UFSCar) (number 1.558.731). All subjects will provide signed informed consent.

The experimental tests and procedures will be performed at the LFCV at the Nucleus of Research in Physical Exercise (NUPEF) at the Department of Physical Therapy (DFisio) and the clinical ergometric tests at the Cardiovascular Physiotherapy area of the School Health Unit (USE), both located at UFSCar, São Carlos campus. The blood tests will be performed at the Clinical Analysis Laboratory at UNIMED (a cooperative medical system) in São Carlos (UNILAB).

Environmental conditions will be controlled, and participants will be instructed according to Perseguini et al. 
[34]. The tests will always be performed in the afternoon, considering the influence of the circadian cycle on the evaluation results.

On the day of the tests, previously to applying the experimental protocols, the conditions related to the participants' state of health will be observed. Moreover, prior to the tests, participants will be familiarized with the equipment, respiratory maneuvers and the subjective perception of effort scale - BORG/ CR10 [35] in order to reduce participants' anxiety and prevent the effect of the learning process from affecting the search results.

\section{Clinical evaluation and characterization of the sample}

Before performing the experimental protocols, the participants will be submitted to the following evaluations: anamnesis, conventional 12-lead ECG and treadmill clinical exercise test, performed in the presence of a cardiologist, assisted by a physiotherapist. The aim of these tests will be the clinical and cardiovascular evaluation of the participants.

To characterize the participants and verify their health status, the following evaluations will be performed before the experimental protocol: body composition evaluation by dual-energy $\mathrm{x}$-ray absorptiometry (DXA) (Discovery DXA System, Hologic, USA), nutritional assessment and blood tests (lipid profile, total cholesterol, high density lipoproteins (HDL), low density lipoproteins (LDL), urea, creatinine, fasting glucose, uric acid, insulin resistance, C-reative protein and glycated hemoglobin, to check their health status.

\section{Experimental protocol}

The experimental protocol will take place over 13 weeks, as shown in Fig. 1. In the 1st, 5th, 9th and 13th weeks, the participants will be submitted to the following evaluations: CPET, RMS, iIME and constant load test (CLT). The PFT will be performed only in the 1st and 13th weeks of the study. The IMT will be carried out for 11 weeks. It is emphasized that the participants will continue doing the training during the reevaluation weeks. The aim of the reevaluations, which will be carried out in the 5th and 9th weeks of training, is to readjust the training loads and to follow the responses to the IMT.

\section{Respiratory muscle strength tests (RMS)}

The evaluation of RMS will be performed with the participants at rest in the sitting position, using a digital manovacuometer (MVD-300, Globalmed, Porto Alegre, Brazil) and a nasal clip, according to the Brazilian guidelines for measuring maximal static respiratory pressures [36]. This measure will always be carried out by the same appraiser.

MIP will be determined after maximal inspiratory effort, from the residual volume. The MEP will be determined after maximal expiratory effort, from total lung capacity. These maneuvers will be performed against a rigid tube, occluded distally and a 2-mm-hole

\begin{tabular}{|c|c|c|c|c|c|}
\hline & \multirow{3}{*}{$\begin{array}{c}\text { Enrolment } \\
-1 \text { month }\end{array}$} & \multicolumn{4}{|c|}{ STUDY PERIOD } \\
\hline & & Allocatio & \multicolumn{3}{|c|}{ Post-allocation } \\
\hline TIMEPOINT & & 0 & $5^{\circ}$ week & $9^{\circ}$ week & $13^{\circ}$ week \\
\hline \multicolumn{6}{|l|}{ ENROLMENT: } \\
\hline \multirow{4}{*}{$\begin{array}{r}\text { Eligibility screen } \\
\text { Infornued consent } \\
\text { Nutritional Evaluation } \\
\text { Allocation } \\
\end{array}$} & $\mathrm{x}$ & & & & \\
\hline & $\mathrm{X}$ & & & & \\
\hline & $\mathrm{x}$ & & & & \\
\hline & & $\mathrm{x}$ & & & \\
\hline \multicolumn{6}{|l|}{ INTERVENTIONS: } \\
\hline \multicolumn{6}{|l|}{$C P G$} \\
\hline \multicolumn{6}{|l|}{$60 G$} \\
\hline \multicolumn{6}{|l|}{$S G$} \\
\hline \multicolumn{6}{|l|}{ ASSESSMENTS: } \\
\hline Blood Test & & $\mathrm{x}$ & & & $\mathrm{x}$ \\
\hline RMS & & $\mathrm{x}$ & $\mathrm{x}$ & $\mathrm{x}$ & $\mathrm{x}$ \\
\hline CPET & & $\mathrm{x}$ & $\mathrm{x}$ & $\mathrm{x}$ & $\mathrm{x}$ \\
\hline$P F T$ & & $\mathrm{x}$ & & & $\mathrm{x}$ \\
\hline iIME & & $x$ & $\mathrm{x}$ & $\mathrm{x}$ & $\mathrm{x}$ \\
\hline$C L T$ & & $\mathrm{x}$ & $\mathrm{x}$ & $\mathrm{x}$ & $\mathrm{x}$ \\
\hline
\end{tabular}

Fig. 1 Template of recommended interventional trials (SPIRIT) schedule. 60G, 60\% of maximal inspiratory pressure group; CLT, constant load test; CPET, cardiopulmonary exercise test; ilME, incremental inspiratory muscle endurance test; $C P G$, critical inspiratory pressure group; $P F T$, pulmonary function test; RMS, respiratory muscle strength test; $\mathrm{SG}$, sham group; sham, $6 \mathrm{cmH}_{2} \mathrm{O}$ 
mouthpiece [36] will be used. The values of the maximal respiratory pressures will be those observed in the first second after the peak of pressure [36]. At least three maneuvers will be performed, with a 30-s interval between each maneuver [37], obtaining the highest reproducible values (difference $<10 \%$ ) found in at least three maneuvers and considering the maximal respiratory pressure as the highest value. Normal values will be based on the regression equation proposed by Neder et al. [38] for the Brazilian population. Respiratory muscle weakness, maximal static pressure values $<60 \%$ of those predicted, will be considered [33].

\section{Cardiopulmonary exercise test (CPET)}

The CPET will be used to assess the aerobic power of the participants' $\mathrm{VO}_{2}$ PEAK [39] to determine the gas exchange threshold (GET) by the ventilatory method [40], the respiratory compensation point (RCP) [39] and inspiratory muscle metaboreflex [41].

A ramp-type protocol will be performed on an electromagnetic braking cycle ergometer (Corival V3, Lode BV, The Netherlands) and will consist of a 6-min rest, 3-min free-load warm up ( 0 watts) and a gradual increase in load until the exercise is stopped, followed by $6 \mathrm{~min}$ active recovery ( 25 watts) and 1 min passive (without pedaling) recovery. The power increment will be calculated for each participant according to the values established by the formula described by Wasserman et al. [42] and adapted according to the evaluator's experience, preventing the increment from being underestimated.

Participants will be instructed to maintain a cadence between 60 and $80 \mathrm{rpm}$ throughout the protocol and the test will last from 8 to $12 \mathrm{~min}$ [42]. Three independent evaluators will determine the GET and the RCP. The highest value of $\mathrm{VO}_{2}$ obtained in the last $30 \mathrm{~s}$ of the CPET will be considered the $\mathrm{VO}_{2 \text { PEAK }}$ [39]. In addition, the following variables will be evaluated in the GET and peak effort: $\mathrm{VO}_{2}, \mathrm{VCO}_{2}, \mathrm{VE}$, OUES and $\mathrm{VE} / \mathrm{VCO}_{2}$ slope [39, 43].

The activation of the inspiratory muscle metaboreflex will be evaluated by analyzing the patterns of the variables: $\mathrm{O}_{2} \mathrm{Hb}, \mathrm{HHb}$ and $\mathrm{tHb}$ obtained by near infrared spectroscopy (NIRS) and the cardiovascular data, HR and mean arterial pressure (MAP), obtained by a bioamplifier for ECG signals (BioAmp FE132) and a Finometer (Finapres Medical Systems, The Netherlands), respectively, at the intensities of $50-100 \%$ of the $\mathrm{VO}_{2 \mathrm{PEAK}}$, subdivided into $10 \%$ intervals. In addition, the activation point of the inspiratory muscle metaboreflex will be considered the moment at which the nonlinear HR, MAP and oxygenation decrease for the vastus lateralis (VL) and increase for the external intercostal (EI), i.e., redirection of blood flow from the peripheral musculature to the respiratory muscles [6].

\section{Pulmonary function test (PFT)}

This examination will be performed according to the international standard [44] and will consist of tests of SVC, FVC and maximal MVV. The test will be performed using a flow module coupled with a system of ventilatory and metabolic measurements (Ultima MedGraphics - St. Paul, MN, USA). The variables to be analyzed are SVC, FVC, $\mathrm{FEV}_{1}, \mathrm{FEV}_{1} / \mathrm{FVC}, \mathrm{IC}$, ERV and MVV. The predicted values will be calculated according to Pereira [45].

\section{Protocol for the determination of critical inspiratory pressure (PThC)}

An incremental protocol with a load of $50-100 \%$ MIP (Fig. 2) will be performed and $10 \%$ of MIP will be added every $3 \mathrm{~min}$. The participant will receive a verbal stimulus to maintain the RR at 12 breaths/minute and the test may continue until he reaches $100 \%$ of MIP. In this case, if the participant can generate an air flow capable of triggering the equipment more than once at this load, the MIP measurement and the test will be repeated. The following will be considered: failure to maintain the stipulated load at 12 breaths/minute for at least $1 \mathrm{~min}$, failure to maintain respiratory effort indicated by the participant (BORG/CR10 $\geq 7$ ) [35] and the participant requesting interruption. The highest percentage of MIP that the participant is able to maintain for at least $1 \mathrm{~min}$ $\left(\mathrm{PTh}_{\mathrm{MA} \mathrm{X}}\right)$ will be stipulated as the IME measurement [26-28, 46].

After determining the $\mathrm{PTh}_{\mathrm{MAX}}$, individuals will carry out incursions against a constant load, without the RR being controlled, in order to identify the total time tolerated in each load $\left(\mathrm{T}_{\text {LIM }}\right)$. Individuals will be exposed to three different resistances (95\%, 100\% and 105\% $\mathrm{PTh}_{\mathrm{MÁX}}$ ) with a 15-min interval between them. The order of resistances will be determined by holding a draw without the individual knowing the order of the charges in which he will be subjected to.

After obtaining the $\mathrm{T}_{\text {LIM }}$ of each load, a pressure graph will be plotted by time and the PThC will be determined by linear regression between the variables [23].

\section{Monitoring the experimental protocol}

The equipment described subsequently will be used to monitor the participants in the evaluations of the CPET and iIME.

\section{Metabolic and respiratory variables}

The ventilatory and metabolic variables will be collected, breath by breath, through a system of expired gas measurements (Ultima MedGraphics - St. Paul, MN, USA) and processed using specific software (Breeze Suite 7.1, MedGraphics - St. Paul, MN, USA). In addition, the 


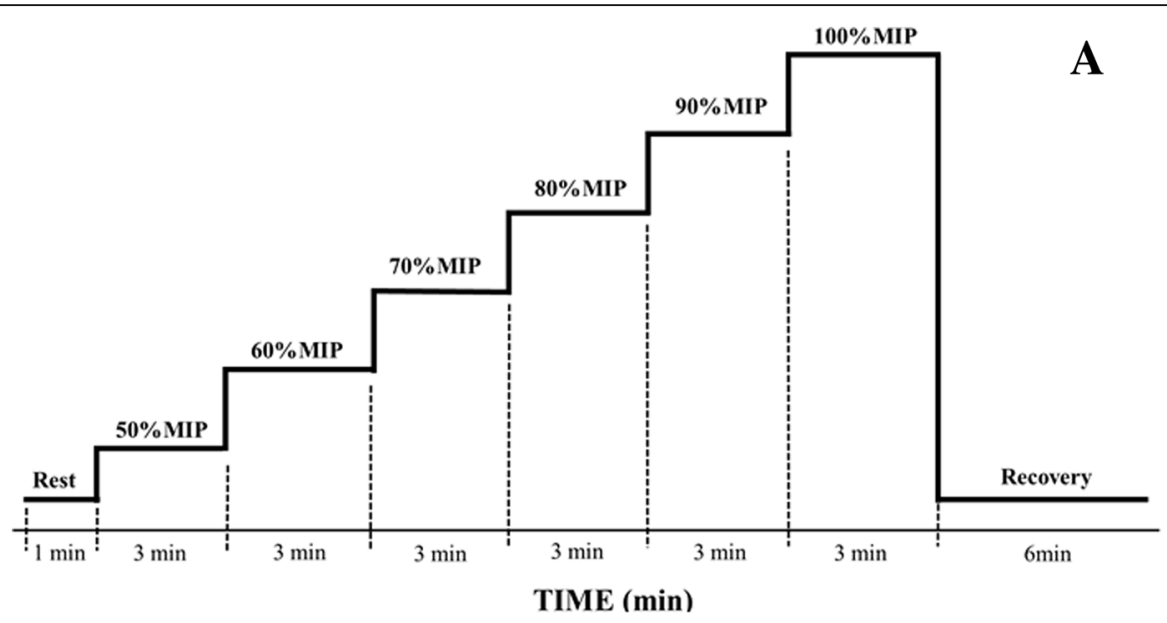

B

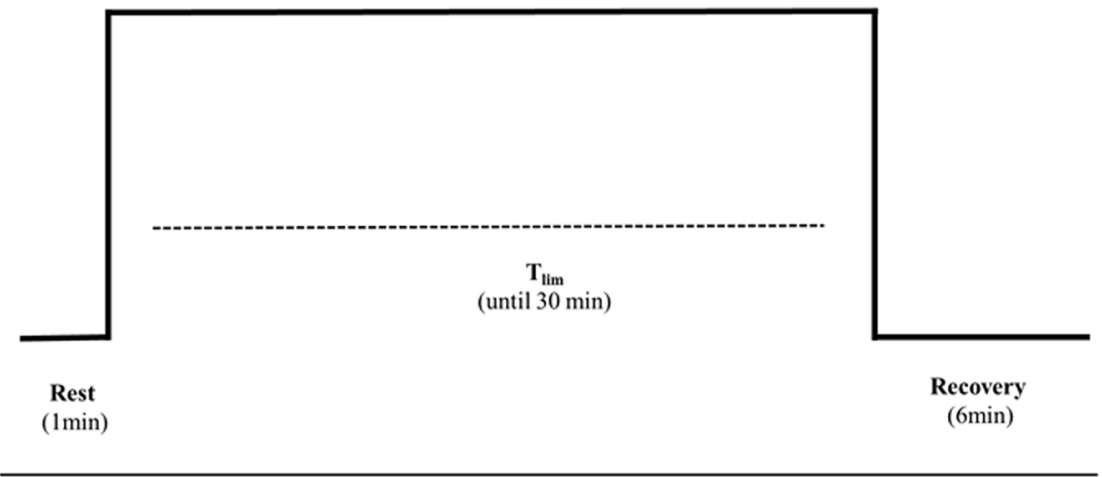

TIME (min)

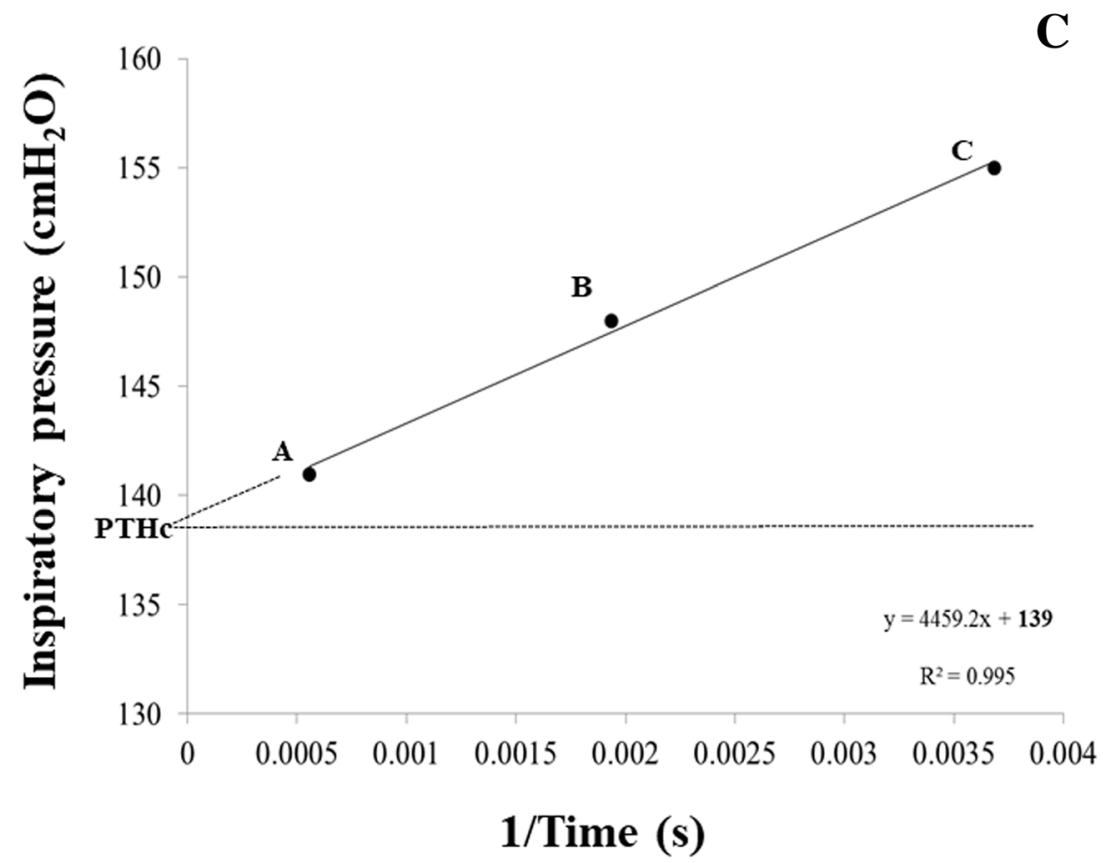

Fig. 2 Description of steps to calculate critical inspiratory pressure. a Incremental inspiratory muscle endurance test. b Constant load test. c Linear regression to determination of critical inspiratory pressure (PThC). MIP, maximal inspiratory pressure; min, minute; REC, recovery 
BORG/CR10 scale [35] will be used to assess the participant's subjective perception of the exercise.

\section{Cardiovascular variables}

The acquisition of the ECG and AP signals to evaluate the cardiovascular responses will be performed at a sampling frequency of $1.000 \mathrm{~Hz}$. The ECG signals will be captured by means of the CM5 lead. The HR will be recorded and stored beat-to-beat. Electrocardiographic signals will be captured and processed via an interface between a bioamplifier for ECG signals (BioAmp FE132, ADInstruments, Australia) and a biological signal acquisition system (Power Lab 8/35, ADInstruments, Australia) and a microcomputer (Intel I5).

On the other hand, pulse pressure will be captured using Finometer Pro $^{\circ}$ (Finapres Medical Systems, The Netherlands), which allows non-invasive measurements of pulse arterial pressure (FinAP), beat-to-beat, obtained by positioning a cuff on the third phalanx of the third finger of the left hand. The equipment will be calibrated according to the manufacturer's instructions. In addition to pulse AP, the values of $\mathrm{CO}, \mathrm{SV}$ and PVR, derived from the AP curves and analyzed using Beat Scope ${ }^{\bullet}$ Easy software (Finapress Medical Systems, The Netherlands) will be evaluated.

\section{Metabolic evaluation by NIRS}

The EI and VL muscle oxygenation variables will be measured by the NIRS (Oxymon Mk III, Artinis Medical Systems, The Netherlands). Two optodes will be used, which will be positioned as described below subsequently: IE = eighth left intercostal space in the anterior axillary line; $\mathrm{VL}=12-15 \mathrm{~cm}$ of the knee joint, lateral line between the greater trochanter of the femur and the patella [47].

The sampling rate of the device will be set at $250 \mathrm{~Hz}$. Inter-ops distance will be $35 \mathrm{~mm}$ for the EI and 40 for the VL [47]. The differential path-length factor (DPF) will be 4 for the EI muscles and 3.83 for the VL. The device will be recalibrated for each subject and the data will be continuously captured during the CPET and the iIME. For each muscle, the change in tissue oxygenation and local blood volume will be estimated by changes in $\mathrm{O}_{2} \mathrm{Hb}, \mathrm{HHb}$ and $\mathrm{tHb}$, calculated automatically by the equipment software using the formula $\left(\mathrm{tHB}=\mathrm{O}_{2} \mathrm{Hb}+\right.$ $\mathrm{HHb})$.

\section{Inspiratory muscle training (IMT) Training description}

The training will last for 11 weeks, with a weekly frequency of three sessions and each session will last $1 \mathrm{~h}$. Each session will consist of a 5-min warm up, where each volunteer will perform a constant loading protocol with $50 \%$ of their training load. The training protocol will consist of three sets of $15 \mathrm{~min}$ of breaths, with a 1-min interval between them (Fig. 3).

The loads that will be used in the training will be as follows: for the CPG the value of the PThC, for the 60G, the resistance will be $60 \%$ of MIP and for the SG, the training will be carried out with a resistance of 6 $\mathrm{cmH}_{2} \mathrm{O}$. All groups will perform IMT using the linear load respiratory (PowerBreathe inspiratory muscle trainer, Ironman K5, HaB Ltd., UK).

The participants will be instructed to maintain diaphragmatic breathing and RR of 12 breaths/minute for the entire duration of the training protocol, and the RR will be controlled using a recorded verbal command, ensuring that all participants receive the same stimulus. During the 11 weeks of training, participants will be instructed not to change their activities and physical training or food intake.

Every day, before and after the training protocol, the AP will be checked, and the health status of the participants will be observed while the HR is monitored, recorded and stored during all training sessions using a Polar 800CX (Kempele, Finland).

In addition, during the training period, the participants will be asked to complete a physical activity schedule to monitor the activities performed by each individual during the research participation and complete a food survey that will be analyzed later by a nutritionist, thus avoiding these factors interfering with training responses. The weekly training volume and the end, will be controlled over 11 weeks and ensured for all participants throughout this study.

Participants who do not complete the three weekly training sessions and/or the total of 33 training sessions will be excluded during the survey, as will participants who change their physical activities or their eating habits or those who begin to use any supplement or medication continuously.

\section{Statistical analysis}

Due to the lack of studies that evaluate the effect of different loads of IMT, among them PThC, on the physical performance in recreational cyclists, we chose to carry out the statistical analysis considering the desired study effect size as proposed by Cohen [48]. Thus, the sample calculation was performed using GPower software 3.1.3 to determine the sample size, the mean effect size $(f=0.25$, according to Cohen [48]) was used for the two-way mixed analysis of variance (ANOVA) and values of 0.05 for the type I probability error $(\alpha)$ and 0.80 for the type II probability error (power or $\beta$ ). Therefore, in order to ensure these pre-established conditions, at least 30 subjects should participate in this study. 


\section{INSPIRATORY MUSCLE TRAINING PROTOCOL}

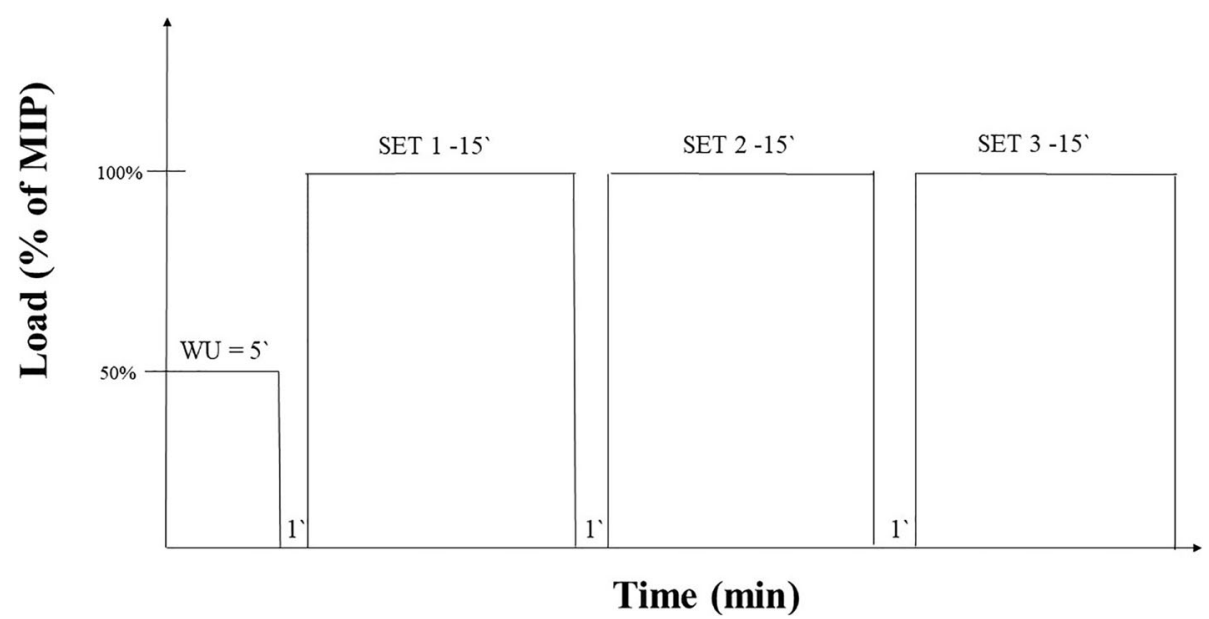

Fig. 3 Schematization of inspiratory muscle training protocol. MIP, maximal inspiratory pressure; min, minute; WU, warm-up

All statistical analyses will be processed using the SPSS Statistics software 17.0 (SPSS Inc., Chicago, IL, USA). The level of significance will be set at $p<0.05$. Normally distributed data will be presented according to the mean \pm standard deviation and non-normally distributed data according to the median (interquartile range).

The Shapiro-Wilk test will be used to test for normal distribution and the Levene test for evaluation of homogeneity. A descriptive analysis of the three groups evaluated and then the paired $t$ test will be performed on the following data: age, anthropometric evaluation, body composition densitometric analysis and blood test results.

The three groups will be compared considering the factors of group and training time, in terms of the variables PFT (FVC, $\mathrm{FEV}_{1} / \mathrm{FVC}$, IC, ERV and MVV), RMS (MIP and MEP), CPET ( $\mathrm{VO}_{2 \mathrm{PEAK}}, \mathrm{VE}, \mathrm{RR}$, OUES and $\mathrm{VE} / \mathrm{VCO}_{2}$ slope), cardiovascular variables ( $\mathrm{HR}, \mathrm{CO}, \mathrm{SAP}$, $\mathrm{SV}$, total PVR) and metabolic variables $\left(\mathrm{O}_{2} \mathrm{Hb}, \mathrm{HHb}\right.$, $\mathrm{tHb}$ and $\left.\mathrm{VO}_{2 \mathrm{PEAK}}\right)$, using two-way mixed ANOVA for parametric data analysis and for non-parametric data analsysis, the data will be mathematically transformed in order to normalize the data.

\section{Expected results}

Among the scientific contributions from this project, the main one refers to adopting a new evaluation methodology (PThC) and prescription of IMT. It is expected that CPG will obtain better results than 60G and SG, such as obtaining a greater increase in workload (Watts) and peak oxygen uptake $\left(\mathrm{VO}_{2 \mathrm{PEAK}}\right)$ in the CPET; higher MIP and iIME; decreased sensation of dyspnea and the sensation of peripheral fatigue, evaluated by the perception index to the physical effort of BORG/CR10 and delay in the activation of the inspiratory muscle metaboreflex both during the CPET and in the iIME.

Thus, it is expected that the use of IMT based on this new approach can increase the benefits derived from traditional methodology (IMT based on $60 \%$ of MIP); that it can provide subsidies on the best understanding of the physiological responses from its application; and that this new methodological approach can be used by health professionals as a new tool to evaluate and prescribe IMT, bringing more satisfactory results and greater physiological impact.

\section{Discussion}

Most systematic reviews [1, 3, 19, 49] that study the effects of IMT emphasize the need for studies with a controlled and randomized experimental design, following the guidelines of the Consolidated Standards of Reporting Trials (CONSORT) [50], and to establish training parameters that seek to achieve the best results for the population studied.

However, adapting this type of training to meet these guidelines becomes extremely complicated because of the need for this therapy to be used in a laboratory. Several experiments, also presented in these reviews [1, 3, 19], perform the training on average five times a day, or often with more than one session on the same day. Therefore, for the results of this research to be discussed considering the studies already published in the literature, we used the determination of the average training volume [51] of these studies, because this is an important 
parameter for determining training effectiveness, mainly resistance. Moreover, we divided the total time into three training days per week, the number of days also indicated by the American College of Sports Medicine [32], as the ideal time for performing physical activities, thus totaling $55 \mathrm{~min}$ of IMT on each day of training.

\section{Contributions to the area}

This study will be important for physiotherapists, physical educators and other health professionals who work with physical exercise and training, as knowledge concerning the cardiovascular, respiratory and metabolic responses generated by IMT in recreational cyclists, using PThC and $60 \%$ of MIP, will enable these professionals to prescribe an IMT in a more suitable way for healthy active individuals. It will also help to encourage new studies that aim to promote greater gains in this population.

It is hoped that the results of this study will enable training performed with PThC to be used by health professionals as a new tool for assessing and prescribing IMT.

\section{Trial status}

Status: participant recruitment is currently underway.

Recruitment began in May 2017.

Final recruitment will be December 2019.

\section{Additional file}

Additional file 1: SPIRIT 2013 checklist: Recommended items to address in a clinical trial protocol and related documents. (PDF $112 \mathrm{~kb}$ )

\section{Abbreviations}

60G: $60 \%$ of maximal inspiratory pressure group; AP: Arterial pressure; BMI: Body mass index; BORG/CR10: Subjective perception of effort scale; CLT: Constant load test; CO: Cardiac output; CONSORT: Consolidated Standards of Reporting Trials; CPET: Cardiopulmonary muscle test: CPG: Critical inspiratory pressure group; DFisio: Department of Physical Therapy; DPF: Differential path-length; DXA: Dual-energy x-ray absorptiometry; ECG: Electrocardiogram; El: External intercostal; ERV: Expiratory reserve volume; $\mathrm{FEV}_{1}$ : Forced expiratory volume in $1 \mathrm{~s} ; \mathrm{FEV}_{1} / \mathrm{FVC}$ : Relationship between $\mathrm{FEV}_{1}$ and FVC; FVC: Forced vital capacity; GET: Gas exchange threshold; HDL: High density lipoproteins; HHb: Deoxyhemoglobin; HR: Heart rate; IC: Inspiratory capacity; IME: Inspiratory muscle endurance; IMS: Inspiratory muscle strength; IMT: Inspiratory muscle training; ilME: Incremental inspiratory muscle endurance test; LDL: Low density lipoproteins; LFCV: Laboratory of Cardiovascular Physiotherapy; MAP: Mean arterial pressure; MEP: Maximal expiratory pressure; MIP: Maximal inspiratory pressure; MW: Maximal voluntary ventilation; NIRS: Near infrared spectroscopy; NUPEF: Nucleus of Research in Physical Exercise; $\mathrm{O}_{2} \mathrm{Hb}$ : Oxyhemoglobin; OUES: Oxygen uptake efficiency slope; PFT: Pulmonary function test; PthC: Critical inspiratory pressure;

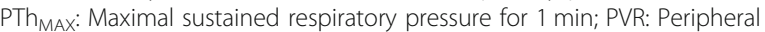
vascular resistance; RCP: Respiratory compensation point; RME: Respiratory muscle endurance; RMS: Respiratory muscle strength test; RR: Respiratory rate; SG: Sham group; SPIRIT: Standard Protocol Items: Recommendations for Interventional Trials; SV: Stroke volume; SVC: Slow vital capacity; tHb: Total hemoglobin; TLM: Inspiratory muscle endurance time; UFSCar: Federal University of São Carlos; UNILAB: Laboratory of Clinical Analysis at UNIMED; UNIMED: Cooperative medical system; USE: Health School Unit; $\mathrm{VCO}_{2}$ : Carbon dioxide production; VE: Pulmonary ventilation; VE $\mathrm{NCO}_{2}$ slope: Minute ventilation-carbon dioxide production slope; $\mathrm{VL}$ : Vastus lateralis; $\mathrm{VO}_{2}$ : Oxygen uptake; $\mathrm{VO}_{2 \text { PEAK: }}$ Peak oxygen uptake; W': Constant of curvature;

$W_{ц \text { M }}$ : Maximal workload

\section{Acknowledgements}

The authors wish to thank the participants of this study and Isabela A. Verzola Aniceto for the clinical assessments.

\section{Funding}

The present study was funded by the National Council for Scientific and Technological Development (CNPq) (\#311938/2013-2) and the São Paulo Research Foundation (FAPESP) (\#2016/22215-7) through Aparecida Maria Catai. The author, Patrícia Rehder dos Santos, was funded by the National Council for Scientific and Technological Development (CNPq) (\#140912/ 2016-9). This study was financed in part by the Coordenação de Aperfeiçoamento de Pessoal de Nível Superior - Brasil (CAPES) - Finance Code 001 . The source of funding had no participation in the study design, data collection and analysis, or writing of the manuscript.

\section{Availability of data and materials}

Not applicable.

\section{Authors' contributions}

PRS, VM and AMC created the idea. PRS, VM, AMC, JCMM, EFS and RMA designed the study and CCD structured the nutritional part. PRS, VM, JCMM, EFS and RMA developed the inspiratory muscle training methodology. AMC guided and coordinated the work. PRS wrote the study and surveyed the literature. Everyone read and reviewed the final version. All authors read and approved the final manuscript.

\section{Ethics approval and consent to participate}

All ethical aspects were considered. The present study will be conducted in accordance with the Helsinki Declaration. This study was approved by the Human Research Ethics Committee at the Federal University of São Carlos (UFSCar) (number 1.558.731). All subjects provide signed informed consent and are registered in the Clinical Trials registry (NCT02984189).

\section{Consent for publication}

Not applicable.

\section{Competing interests}

The authors declare that they have no competing interests.

\section{Publisher's Note}

Springer Nature remains neutral with regard to jurisdictional claims in published maps and institutional affiliations.

\section{Author details}

${ }^{1}$ Cardiovascular Physical Therapy Laboratory, Nucleus of Research in Physical Exercise, Department of Physical Therapy, Federal University of São Carlos, Via Washington Luiz, km 235, CP: 676, São Carlos, São Paulo 13565-905, Brazil.

${ }^{2}$ Nutrition Course, Central University of Paulista, São Carlos, São Paulo, Brazil.

Received: 24 December 2018 Accepted: 3 April 2019

Published online: 07 May 2019

References

1. Cahalin LP, Arena R, Guazzi M, Myers J, Cipriano G, Chiappa G, et al. Inspiratory muscle training in heart disease and heart failure: a review of the literature with a focus on method of training and outcomes. Expert Rev Cardiovasc Ther. 2013;11(2):161-77.

2. Cahalin LP, Arena RA. Breathing exercises and inspiratory muscle training in heart failure. Heart Fail Clin. 2015;11(1):149-72.

3. HajGhanbari B, Yamabayashi C, Buna TR, Coelho JD, Freedman KD, Morton $\mathrm{TA}$, et al. Effects of respiratory muscle training on performance in athletes: a systematic review with meta-analyses. J Strength Cond Res. 2013;27(6): 1643-63.

4. Edwards AM, Cooke CB. Oxygen uptake kinetics and maximal aerobic power are unaffected by inspiratory muscle training in healthy subjects 
where time to exhaustion is extended. Eur J Appl Physiol. 2004;93(1-2): 139-44.

5. Gething AD, Williams $M$, Davies $B$. Inspiratory resistive loading improves cycling capacity: a placebo controlled trial. Br J Sports Med. 2004;38(6): 730-6.

6. Sheel AW. Respiratory muscle training in healthy individuals: physiological rationale and implications for exercise performance. Sports Med. 2002;32(9): 567-81.

7. Fairbarn M, Coutts K, Pardy R, McKenzie D. Improved respiratory muscle endurance of highly trained cyclists and the effects on maximal Exercise performance. Int J Sports Med. 1991;12(01):66-70.

8. Holm P, Sattler A, Fregosi RF. Endurance training of respiratory muscles improves cycling performance in fit young cyclists. BMC Physiol. 2004;4:9

9. Jakovljevic DG, McConnell AK. Influence of different breathing frequencies on the severity of inspiratory muscle fatigue induced by high-intensity front crawl swimming. J Strength Cond Res. 2009;23(4):1169-74.

10. Johnson MA, Sharpe GR, Brown PI. Inspiratory muscle training improves cycling time-trial performance and anaerobic work capacity but not critical power. Eur J Appl Physiol. 2007;101(6):761-70.

11. Kilding AE, Brown S, McConnell AK. Inspiratory muscle training improves 100 and 200 m swimming performance. Eur J Appl Physiol. 2010;108(3): 505-11.

12. Mickleborough TD, Nichols T, Lindley MR, Chatham K, lonescu AA. Inspiratory flow resistive loading improves respiratory muscle function and endurance capacity in recreational runners: inspiratory muscle training and running. Scand J Med Sci Sports. 2009;20(3):458-68.

13. Sonetti DA, Wetter TJ, Pegelow DF, Dempsey JA. Effects of respiratory muscle training versus placebo on endurance exercise performance. Respir Physiol. 2001;127(2-3):185-99.

14. Wells GD, Plyley M, Thomas S, Goodman L, Duffin J. Effects of concurrent inspiratory and expiratory muscle training on respiratory and exercise performance in competitive swimmers. Eur J Appl Physiol. 2005;94(5-6): 527-40

15. Wylegala JA, Pendergast DR, Gosselin LE, Warkander DE, Lundgren CEG. Respiratory muscle training improves swimming endurance in divers. Eur J Appl Physiol. 2007;99(4):393-404.

16. Sturdy G, Hillman D, Green D, Jenkins S, Cecins N, Eastwood P. Feasibility of high-intensity, interval-based respiratory muscle training in COPD. Chest 2003;123(1):142-50.

17. Hill K, Jenkins SC, Philippe DL, Shepherd KL, Hillman DR, Eastwood PR. Comparison of incremental and constant load tests of inspiratory muscle endurance in COPD. Eur Respir J. 2007:30(3):479-86.

18. Powers SK, Criswell D, Lieu F-K, Dodd S, Silverman H. Diaphragmatic fiber type specific adaptation to endurance exercise. Respir Physiol. 1992;89(2): 195-207.

19. Janssens L, Brumagne S, McConnell AK, Raymaekers J, Goossens N, Gayan-Ramirez G, et al. The assessment of inspiratory muscle fatigue in healthy individuals: a systematic review. Respir Med. 2013:107(3): $331-46$

20. Minatel V. Análise das respostas ventilatórias, metabólicas e do controle autonômico cardiovascular durante testes de resistência muscular inspiratória e de determinação da pressão inspiratória e de determinação da pressão inspiratória crítica. São Carlos: Universidade Federal de São Carlos; 2017. [cited 29 Nov 2018]. Available from: https://repositorio.ufscar. br/handle/ufscar/10705

21. Monod H, Scherrer J. The work capacity of a synergic muscular group. Ergonomics. 1965;8(3):329-38

22. Hill DW. The critical power concept: a review. Sports Med. 1993;16(4): 237-54.

23. Jones AM, Vanhatalo A, Burnley M, Morton RH, Poole DC. Critical power: implications for determination of $\mathrm{V}^{\prime} \mathrm{O} 2 \mathrm{max}$ and exercise tolerance. Med Sc Sports Exerc. 2010;42(10):1876-90

24. Moritani T, Nagata A, Devries HA, Muro M. Critical power as a measure of physical work capacity and anaerobic threshold. Ergonomics. 1981;24(5): 339-50

25. Vanhatalo A, Doust JH, Burnley M. Determination of critical power using a 3-min all-out cycling test. Med Sci Sports Exerc. 2007;39(3):548-55.

26. Dall'Ago P, Chiappa GRS, Guths H, Stein R, Ribeiro JP. Inspiratory muscle training in patients with heart failure and inspiratory muscle weakness: a randomized trial. J Am Coll Cardiol. 2006;47(4):757-63.
27. Eastwood PR, Hillman DR, Morton AR, Finucane KE. The effects of learning on the ventilatory responses to inspiratory threshold loading. Am J Respir Crit Care Med. 1998;158(4):1190-6.

28. Neves LMT, Karsten M, Neves VR, Beltrame T, Borghi-Silva A, Catai AM. Relationship between inspiratory muscle capacity and peak exercise tolerance in patients post-myocardial infarction. Heart Lung. New York, United States. 2012;41(2):137-45.

29. Neves LF, Reis MH, Plentz RDM, Matte DL, Coronel CC, Sbruzzi G. Expiratory and expiratory plus inspiratory muscle training improves respiratory muscle strength in subjects with COPD: systematic review. Respir Care. 2014;59(9): 1381-8

30. Chan A-W, Tetzlaff JM, Altman DG, Laupacis A, Gøtzsche PC, Krleža-Jerić K, et al. SPIRIT 2013 statement: defining standard protocol items for clinical trials. Rev Panam Salud Publica Pan Am J Public Health. 2015;38(6):506-14.

31. AHA. Exercise testing and training of apparently healthy individuals: a handbook for physicians: Universidade de Michigan. Dallas: American Heart Association; 1972. p. 40.

32. Garber CE, Blissmer B, Deschenes MR, Franklin BA, Lamonte MJ, Lee I-M, et al. Quantity and quality of exercise for developing and maintaining cardiorespiratory, musculoskeletal, and neuromotor fitness in Apparently healthy adults: guidance for prescribing exercise. Med Sci Sports Exerc. 2011;43(7):1334-59.

33. Hautmann $\mathrm{H}$, Hefele $\mathrm{S}$, Schotten $\mathrm{K}$, Huber RM. Maximal inspiratory mouth pressures (PIMAX) in healthy subjects - what is the lower limit of normal? Respir Med. 2000;94(7):689-93.

34. Perseguini NM, de Medeiros Takahashi AC, Milan JC, dos Santos PR, Neves VFC, Borghi-Silva A, et al. Effect of hormone replacement therapy on cardiac autonomic modulation. Clin Auton Res. 2014:24(2):63-70.

35. Borg GA. Psychophysical bases of perceived exertion. Med Sci Sports Exerc. 1982;14(5):377-81.

36. Souza RB. Pressões respiratórias estáticas Máximas. J Pneumol. 2002;28(3): 155-64.

37. Romer LM, McConnell AK. Inter-test reliability for non-invasive measures of respiratory muscle function in healthy humans. Eur J Appl Physiol. 2004; 91(2-3):167-76.

38. Neder JA, Andreoni S, Lerario MC, Nery LE. Reference values for lung function tests: II. Maximal respiratory pressures and voluntary ventilation. Braz J Med Biol Res. 1999:32(6):719-27.

39. Balady GJ, Arena R, Sietsema K, Myers J, Coke L, Fletcher GF, et al. Clinician's guide to cardiopulmonary exercise testing in adults: a scientific statement from the American Heart Association. Circulation. 2010;122(2):191-225.

40. Higa MN, Silva E, Neves VFC, Catai AM, Gallo L Jr, Silva de Sá MF. Comparison of anaerobic threshold determined by visual and mathematical methods in healthy women. Braz J Med Biol Res. 2007;40(4):501-8.

41. Dempsey JA, Sheel AW, St Croix CM, Morgan BJ. Respiratory influences on sympathetic vasomotor outflow in humans. Respir Physiol Neurobiol. 2002; 130(1):3-20

42. Wasserman $\mathrm{K}$, editor. Principles of exercise testing and interpretation: including pathophysiology and clinical applications. 5th ed. Philadelphia: Wolters Kluwer Health/Lippincott Williams \& Wilkins; 2012. p. 572.

43. Castello-Simões V, Minatel V, Karsten M, Simões RP, Perseguini NM, Milan JC, et al. Circulatory and ventilatory power: characterization in patients with coronary artery disease. Arq Bras Cardiol. 2015.

44. American Thoracic Society/European Respiratory Society. ATS/ERS Statement on respiratory muscle testing. Am J Respir Crit Care Med. 2002;166(4):518624.

45. Pereira CA de C, Sato T, Rodrigues SC. Novos valores de referência para espirometria forçada em brasileiros adultos de raça branca. J Bras Pneumol. 2007;33(4):397-406.

46. Neves LMT, Karsten M, Neves VR, Beltrame T, Borghi-Silva A, Catai AM Respiratory muscle endurance is limited by lower ventilatory efficiency in post-myocardial infarction patients. Braz J Phys Ther. 2014;18(1):1-8

47. Shadgan B, Guenette JA, Sheel AW, Reid WD. Sternocleidomastoid muscle deoxygenation in response to incremental inspiratory threshold loading measured by near infrared spectroscopy. Respir Physiol Neurobiol. 2011 178(2):202-9.

48. Cohen J. Statistical power analysis for the behavioral sciences. 2nd ed. New York: Taylor \& Francis Inc.; 1988.

49. de Abreu RM, Rehder-Santos P, Minatel V, Dos Santos GL, Catai AM. Effects of inspiratory muscle training on cardiovascular autonomic control: A 
systematic review. Auton Neurosci. 2017;208:29-35. https://doi.org/10.1016/j. autneu.2017.09.002. Epub 2017 Sep 7.

50. Schulz KF, Altman DG, Moher D, for the CONSORT Group. CONSORT 2010 Statement: updated guidelines for reporting parallel group randomised trials. BMJ. 2010;340(mar23 1):c332.

51. Burd NA, Holwerda AM, Selby KC, West DWD, Staples AW, Cain NE, et al. Resistance exercise volume affects myofibrillar protein synthesis and anabolic signalling molecule phosphorylation in young men: resistance exercise volume and myofibrillar protein synthesis. J Physiol. 2010;588(16): 3119-30.

Ready to submit your research? Choose BMC and benefit from:

- fast, convenient online submission

- thorough peer review by experienced researchers in your field

- rapid publication on acceptance

- support for research data, including large and complex data types

- gold Open Access which fosters wider collaboration and increased citations

- maximum visibility for your research: over $100 \mathrm{M}$ website views per year

At BMC, research is always in progress.

Learn more biomedcentral.com/submissions 